\title{
Psychological Problem Factors Faced by Staff Nurses Working in Hospitals
}

\author{
${ }^{1}$ K. Srinivasan, ${ }^{2}$ Dr. A. Umesh Samuel \\ ${ }^{I}$ Research Scholar, Department of Social Work, Bishop Heber College, India \\ ${ }^{2}$ Associate Professor, Department of Social Work, Bishop Heber College, India
}

\begin{abstract}
The paper aims to describe perceived psychological problems faced by Staff Nurses working in hospitals. There by the paper illustrates Professional, Personality, Stress and Situational factors that are felt contributing in explaining the psychological problems of Staff nurses working in hospitals. Various coping strategies such as curative, proactive and preventive methodologies to overcome such psychological problems that are discussed are explained as a part of the study. The paper concludes with giving elaborate details of psychological problems of staff nurses both intrinsic and extrinsic and how significant is to address them as their service to humanity to a large extent would be affected if left without suitable treatment.
\end{abstract}

\section{Introduction}

Nursing is, by its very nature, an occupation exposed to stressful work load which in turn is linked with poor physical and psychological health. Likewise patients approaching hospitals are themselves suffering a considerable degree of stress often being difficult, frightened and resentful. Staff Nurses working in hospitals have to find themselves responding with a growing sense of irritability and frustration. In the absence of doctors, nurses are on the front line and have to face verbal abuse from patients and relatives for issues that may not be directly connected to their work. Physical violence and aggressiveness is also on the rise in patients and their relations. Demanding patients and their relatives can cause conflict and lead to more stress. Patients' expectations from nurses in a hospital setting are sometimes unreasonable and they tend to be aggressive. Staff Nurses can easily become disillusioned, cynical, depressed with the condition of Stress. Thus this study paper discusses the psychological problem factors of Nurses working in hospitals.

\section{Aims and Objectives}

The study paper is concerned with the following main aims and objectives

1. To describe Professional factors causing physiological cum psychological disorders among Staff Nurses working in hospitals.

2. To portray personality factors that affect psychosomatic conditioning Staff Nurse.

3. To explain about Stress factors of Staff Nurses working in hospitals.

4. To illustrate situational factors those influence emotional well being of Staff Nurse.

\section{Professional Factors in Nursing Care}

All Staff Nurses have to do shift work or attend emergencies at night. The stress of shift work can also weaken health conditions and lead to heart disease or digestive disorders. Low energy can lead to error, injury, and carelessness. Long hours are a source of depression, low morale, and low motivation. Shift workers are on the job in the evening or on weekends and they sleep during the day. Hence, they often miss out on social or family activities. This can have a negative influence on their physical and emotional health and lead to psychosomatic disorders. The pressures of overtime and long working hours create a work-personal life imbalance, which begins to affect the mental health of the Staff Nurses and undermine their relationship at home as well as on the job. Lack of professional respect and recognition by authorities and doctors considered as the major cause of dissatisfaction in nurses. Poor relationship with physicians was related to musculoskeletal disorders, which is seen as the most important reason for nurses leaving hospitals. Lack of autonomy, poor participation in patient care due to lack of sufficient knowledge and empowerment deprives them from job satisfaction.

Staff Nurses in India are mainly from the lower economic strata and have low educational qualifications. Their main motivators are salary and benefits to support their home and maintain a decent standard of living. Shortage of staff makes them easily succumb to increasing their pay package by doing excessive hours of overtime at the expense of their health. They have limited access to claims and compensation for occupational hazards. Other factors such as long commuting hours and chaotic traffic conditions also affect their efficiency and effectiveness. 


\section{Personality Factors in Nursing Care}

A number of personality factors include perfectionism, over-involvement with patients, self-esteem, sense of mastery and purpose in life (Sherman, 2004), low education level, low work experience, low status, economic hardships, difficulty in childcare and doing house chores, and personal and family health problems (Demir, Ulusoy, et.al., 2003). This means that a person who has poor valuation of herself, and one who has inadequate training and poor perception of skills may more likely to encounter stress compared with someone who has positive self-efficacy.

Staff Nurses' personalities and qualities may be expected to leave a special mark on their interrelationships with patients and thereby affect the quality of care. Theorists of nursing care have called attention to some important concepts in this context (Henderson, 1966; Travelbee, 1971; Orlando, 1990; Peplau, 1991). These concepts are: empathy; interest; self-conception; having a sensitive ear and apprehending body language; interaction; communication; and the ability to maintain a distance, as demonstrated by giving back what was figured out. The personality type of oncology nurses, according to the typology defined by Carl Jung, was found to be the type where feeling is introverted and perception is practical, so that helping others is both a responsibility and a pleasure (Bean \& Holcombe, 1993). Five models of nursing activities, related to Staff Nurses' attitudes to patients, were identified by Liukkonen (1992): 'cassette-like' and 'skilful' nursing care' where the interaction was found to be warm, protective, friendly and humane; or 'rejective', 'routinised' and 'robot-like' nursing care that was mainly task-oriented.

Feelings of hatred are, together with feelings of annoyance, joy, grief, humiliation etc., included among the inherited and universal reactions and emotions that people can have. For someone working in a nursing profession, there are many incidences that provoke feelings of hatred and revulsion. Staff Nurses have, for example, reported strong feelings of mental strain in situations connected with dressing of ulcerous cancer wounds or being too close to the patient (Pålsson et al., 1995). Emotions that may be evoked by 'body work', i.e. disgust, contempt or aversion, influence the social relations between patients and staff (van Dongen, 2001). Despite this, there are few studies in this area. One explanation can be that feelings of hatred and revulsion are associated with humiliation and that this brings about a resistance to the study of these phenomena. Other types of feelings of discomfort have been studied in relation to personality traits, such as dealing with physical pain, monotony and discomfort facing other people's judgment (Pettersson \& Sköld, 1972).

\section{1. Expected Personality outlook for Nursing Profession}

Empathy is regarded as being very significant and important in caring work, since the interpersonal interaction between nurse and patient is considered to be the focus of nursing care (Svärdson, 1999). The nurse's individual qualities are thus of great importance (Chinn \& Jacobs, 1983). Empathy is thought to have an effect on the patient's emotions; among other things it may bring a heightened self-respect. The empathic encounter is considered to have a curative effect in itself (Halldorsdottir, 1996). In addition, the empathic encounter is regarded as a cornerstone of the therapeutic alliance, which is a prerequisite for successful psychotherapeutic treatment (Kohut, 1988). The nurse-patient encounter can be interpreted as being characterized by either empathy or self-regulating, apparently leading to feelings of approval or disapproval of each other. A high quality encounter strengthens the identity of patients as well as of Staff Nurses by mutual acceptance. Staff Nurses experience in these encounters that their identity as a good nurse has been complete.

\section{3. Stress Factors in Nursing Care}

Due to risky and exhausting nature of the nursing profession the psychological condition of the Staff Nurses working in hospitals is determined by Job stressors corresponding with various health effects. Stress when considered a workplace issue the framework of work-related factors affecting Stress can be individual, Group, Organizational and Environmental. Hence by looking into possible insights the management can promote value addition and self-enrichment programs that may prevent or reduce Stress. Similarly, a significant contribution by risk exposure would mean that Stress may now be considered as a profession related illness, and must be considered for possible compensation. Similarly Role stress has to be dealt with proper role definition and role clarity. Nursing as a profession by its nature involves lot of physical and emotional strength along with required professional knowledge to deal with patients in a deliberate sense.

\section{1. Importance of Coping up with Stress for a Nursing Profession}

Stress endurance and coping style is of great importance for Nurses Job satisfaction. Coping strategies are various kinds of activities used to diminish the experience of stress. The strategy can be dynamic or submissive, problem-oriented or emotion oriented. Effective coping strategies are also helpful to a professional conduct. What is required is adjustment to the demands of the relationships with patients as well as the demands of the work tasks. In addition to this, a professional conduct comprises the abilities of distance-keeping and 
reflection, which presuppose mature ego functions. The ability to find strategies to prioritize between conflicting interests is considered to be among the special qualities that nurses require.

\subsection{Psychological Implications of Stress among Nurses}

Stress is experienced when demands made on us outweigh our resources. A moderate level of stress or "Eustress" is a significant inspiring factor and is considered usual and essential. If stress is severe, constant, and recurring, it becomes a harmful experience or "Distress," which can lead to physical ill health and psychosomatic disorders. Psychosomatic illnesses are disorders that involve both the body and the mind. These illnesses are mental or emotional in origin and have physical symptoms. Running health institutions as a commercial industry has changed the pattern of nursing care and the profession inclusively. Stress levels are on increasing trends and little is being done about assessing this problem and keenly managing its effects. Staff Nurses are expected to give responsive quality patient care, have patience, and help disposition and, at the same time, save costs and increase competence by delivering a rapid output.

\section{3. Physiological demands in Nursing}

All Staff Nurses have to do shift work or attend emergencies at night. The stress of shift work can also aggravate health conditions and lead to heart disease or digestive disorders. Fatigue can lead to error, injury, and carelessness. Long hours are a source of depression, low morale, and low motivation. Shift workers are on the job in the evening or on weekends and they sleep during the day. Hence, they often miss out on social or family activities. There is a severe difference in causes of stress in nurses in developed countries than in India. Staff Nurses salaries in India are poor when compared to the world standards. For the kind hard work that the Staff Nurses do, the salary and benefits are not adequate. Rewards not proportional to workload are a source of great stress as it is difficult to have decent standards of living based only on their salary that are remunerated.

\subsection{Professional approaches to tackle stress among Nurses}

Chronic stress lessens motivation thus leading to increased absenteeism and increased turnover and attrition rates. It is essential for healthcare organizations to address this issue urgently for proactive stress management, especially preventive strategies that are encouraged in industries such as IT sectors. The coping techniques like team building, counseling, learning assertiveness and communication skills has to be taught to all Staff Nurses, even incorporated in their training curriculum as well. Elimination of all stressors is a utopian goal. Effective solutions can be addressed such as increasing skills, enriching work, and increasing the participation of nurses in other health related managerial aspects of the organization. Sufficient staffing, which reduces job stress and overtime, could lead to better efficiency along with cost control.

Every health care institution should assess the degree of stress and analyze it to recognize the need for necessary action. Stress assessment done through such "stress audit" has to be considered for meaningful implication. Earlier, stress was viewed as an individual problem to be dealt with palliative or remedial measures. Now, moving forward is to be proactive, with emphasis on prevention and elimination rather than treatment. Improving the quality of work life of Staff Nurses may go a long way to decrease attrition.

\section{Situational Factors in Nursing Care}

Situational factors such as problems with physicians, aggressive and criminal patients, nevertheless undervaluing public and Staff Nurses' physical and emotional constraints of the workplace, co-nurse relationships, horizontal and vertical violence due to seniority, gender bias, personal cast and creed preferences or differences, sexual torture and favoritism. Dealing with difficult or demanding patients can also be unsafe situation. Marital demands and in particular if both are working couples their commitment clash in children procreation, growth, education and development are pressures unavoidable.

Nursing staff ought to be compassionate and insightful to a range of open signals and, at the same time, to have a high threshold of broadmindedness for situations provoking physical discomfort. It is also necessary to be able to bear the patient's expressions of difficult emotions such as nervousness and ache. In other words: a nurse must keep her heart modest and her head bitter. Nursing competency of some quality requires a professional management and good coping strategies. Professional management in nursing care embraces the demands of the relationship as well as the demands of the work and, in addition, the ability of distanced reflection. There can be two demands upon a professional management in nursing care. The first amounts to accepting that the relationship with the patient is not equal and mutual. A professional Nurse is deemed to include the ability to interpret patients' needs - needs that are expressed more or less clearly. These demand physical as well as mental presence. A prerequisite here is expertise of the technical aspects of the work. With such expertise the nurse does not have to focus on their own acting and can instead devote their full attention to the patient. Second, a professional management in nursing care involves the ability to be empathic and to establish contact with the patient emotionally, but also to maintain an emotional distance when this is called for. 
For example, the patient's anxiety should not lead to anxiety in the nursing staff. Being able to shift as called for between closeness and an objective attitude towards the patient requires well-developed ego functions and good coping strategies.

Good coping strategies are also expected when confronting other types of stress and anxiety provoking situations in nursing care. Nursing care demands a peaceful mind, complete presence and full attention to the current patient, but nursing situations may cause feelings of discomfort to an uneven range. Specific stress-provoking situations can have different significance for different health workers. The apprehension that young children or young people may aggravate, for example, can lead to individually differing strategies of defense, such as that of detachment, which can disfavor the beneficiary. In many nursing care situations, patience is inevitable but may be subjected to a severe experiment.

\section{Conclusion}

Staff Nurses are the backbone of any healthcare unit. Staff Nurses need recognition and encouragement. They deserve to be treated with deep respect in society. A Staff nurse takes gentle care of patients to save their lives or cure their illness just as a loving mother or a sister or a member of the family. Nurses do service to humanity and so also called as a 'Sister' or 'Brother' or as a 'Master'. Issues relating to their psychosocial condition and coping measures should receive sympathetic consideration. While taking care of the health of others, it is important that Staff Nurses should learn and use the methods and techniques to take care of their own health also. Staff Nurses need recognition and encouragement. They deserve to be treated with deep respect in society.

\section{References}

\section{Journals}

[1] Bakker, A. B., Demerouti, E. and Schaufeli, W. B. The crossover of burnout and work engagement among working couples. Human Relations. 2005, Vol. 58, No. 5, 661-689.

[2] Begat, I., Ellefsen, B. Severinsson, E. Nurses'satisfaction with their work environment and the outcomes of a clinical nursing supervision on nurses' experiences of wellbeing -a Norwegian study. Journal of Nursing Management. 2005 May; 13 (3): $221-30$.

[3] Chen-Chung Ma, Michael E. Samuels, W. Alexander (2003)." Factors That Influence Nurse's Job Satisfaction”, Journal of Nursing Administration, Vol. 33 No. 5, pp. $293-299$

[4] Demir A, Ulusoy M, Ulusoy MF. Investigation of factors influencing burnout levels in the professional and private lives of nurses. International Journal of Nursing Studies. 2003 Nov; 40 (8):807-27.

[5] Edwards, D., Burnard, P., Coyle, D., Fothergill, A., Hannigan, B. Stress and Burnout in Community Mental Health Nursing: a review of the literature. Journal of Psychiatric and Mental Health Nursing. February 2000; 7 (1):7.

[6] Fletcher, C. E. (2001). "Hospital RN's job satisfactions and dissatisfactions". Journal of Nursing Administration, Vol. 31 No. 6, pp. 324-31

[7] Journal of International Women's Studies Vol. 9 \#3 May 200877 Dorz S, Novara C, Sica C, Sanavio E. Burnout syndrome among health workers caring for AIDS patients: predictive variables. G Ital Med Lav Ergon. 2004 Apr-Jun; 26(2):114-8.

[8] Jennifer L. Kettle R. N (2002)." Factors Affecting Job Satisfaction in the Registered Nurse", Journal of Undergraduate Nursing Scholarship, College of Nursing

[9] McVicar A (2003).” Work place stress in Nursing”, Journal of Advanced Nursing, Vol. 44, No. 6, pp.633-642.

[10] Shirey, M. R. Authentic Leaders Creating Healthy Work Environments for Nursing Practice. American Journal of Critical Care. 2006, 15: 256-267.

[11] Tankha, G. A Comparative Study of Role Stress in Government and Private Hospital Nurses. Journal of Health Management. 2006, Vol. 8, No. 1, 11-22.

[12] Taylor B, Barling J. Identifying sources and effects of career fatigue and burnout for mental health nurses: a qualitative approach. International Journal of Mental Health Nursing. 2004 Jun; 13(2):117-25.

Books

[13] Cherniss, C. Professional burnout in human service organizations. New York: Praeger; 1980.

[14] Golembiewski, R. T., \& Munzenrider, R. Phases of burnout: Developments in concepts and applications. (New York: Praeger; 1988).

[15] Kothari C R (2008), Research Methodology, (New Age International Publishers, New Delhi).

\section{Book Reviews and Study Papers}

[16] Bennett, S., Plint, A. and Clifford, T. J. Burnout, psychological morbidity, job satisfaction, and stress: a survey of Canadian hospital based child protection professionals. Archives of Disease in Childhood. 2005; 90:1112-1116.

[17] Borritz, M., Rugulies, R., Christensen, K. B., Villadsen, E. and Kristensen, T. S. Burnout as a predictor of self-reported sickness absence among human service workers: prospective findings from three year follow up of the PUMA study. Occupational and Environmental Medicine. 2006, 63:98 106.

[18] Cohen-Katz J, Wiley SD, Capuano T, Baker DM, Shapiro S. The effects of mindfulness based stress reduction on nurse stress and burnout: a quantitative and qualitative study. Holistic Nursing Practice. 2004 Nov-Dec; 18(6):302-8.

[19] Ernst M.E, Franco M, Messmer P R and Gonzalez J L. (2004) "Nurses' Job Satisfaction, Stress, and Recognition in a Pediatric Setting" Pediatric Nursing; Vol. 30, No.3, pp. 219-227

[20] Hassmiller, S. B. and Cozine, M. Addressing the Nurse Shortage to Improve the Quality of Patient Care. Health Affairs 2006, 25, no. $1268-274$.

[21] Hsieh CJ, Hsieh HY, Chen PH, Hsiao YL, Lee S. The relationship between hardiness, coping strategies and burnout in psychiatric nurses Hu Li Za Zhi. 2004 Jun; 51(3):24-33.

[22] Kirkcaldy B D, Martin T (2000). "Job stress and satisfaction among nurses: individual differences", Stress Medicine, Vol. 16, No. 2, pp.77-89

[23] McNeese-Smith, D. (2001). "Staff nurse views of their productivity and non productivity", Heath Care Management Review, Vol. 26, No. 2, pp. 7-19.

[24] Timothy Bartram, Therese A Joiner and Pauline Stanton (2004)." Factors Affecting the Job Stress and Job Satisfaction of Australian Nurses: Implications for recruitment and retention", Contemporary Nurse, Vol. 17, No. 3, pp. 293-303

[25] Toscano, P. and Ponterdolph, M. (1998). "The personality to buffer burnout", Nursing Management, Vol. 29, No. 8, pp. 38-41. 